\title{
Entre lo internacional y lo nacional-étnico: los voluntarios judíos de Palestina y Argentina en la Guerra Civil española
}

\author{
RAANAN REIN \\ Tel Aviv University (Israel) \\ orcid.org/0000-0002-0249-6084 \\ Presentación: 5 dic. 2019 | Aceptación: 11 mar. 2020 | Publicación: 31 oct. 2020
}

Cita recomendada: Rein, Raanan. 2020. «Entre lo internacional y lo nacional-étnico: los voluntarios judíos de Palestina y Argentina en la Guerra Civil Española». Dictatorships \& Democracies. Journal of History and Culture 8: 47-75. doi: https://dx.doi.org/10.7238/dd.voi8.3169

Resumen: La Guerra Civil española provocó fuertes debates en todos los países de Occidente. La opinión pública internacional liberal y de izquierdas se movilizó en favor de la Segunda República y los valores que supuestamente representaba: democracia, progreso y justicia social. El apoyo a la República se manifestó también a través de la decisión de decenas de miles de voluntarios de todo el mundo de viajar a la península ibérica y defenderla en las trincheras. Para analizar este fenómeno desde una perspectiva global, hay que tener en cuenta que el número de voluntarios judíos que se enrolaron en las Brigadas Internacionales fue muy elevado. Aunque existe una bibliografía sobre los voluntarios europeos o estadounidenses judíos, hay una conspicua ausencia en la historiografía sobre la presencia de argentinos judíos que lucharon en la Guerra Civil española, y existen muy pocos trabajos sobre los voluntarios judíos que salieron de Palestina. Este artículo se centra en estos dos grupos y destaca algunas figuras judías que nos sirven para entender mejor el compromiso de miles de judíos con la República Española. Palabras clave: Guerra Civil Española, Argentina, Palestina, Brigadas Internacionales, voluntarios judíos, Mika Feldman, Pinchas Cheifetz

Between the International and the Ethnic-National Perspectives: Jewish Volunteers from Palestine and Argentine in the Spanish Civil War

Abstract: The Spanish Civil War provoked heated debates in all Western countries. Liberal and left-wing public opinion mobilized on behalf of the Second Spanish Republic and the values it supposedly represented: democracy, progress, and social justice. Support of the Republic was also expressed in the decision of tens of thousands of young people around the world to travel to the Iberian Peninsula and defend the Republic in the Spanish trenches. The number of Jewish volunteers who joined the International

Nota: Me gustaría agradecer al Israel Institute de Washington D. C. el apoyo prestado en la investigación que tuvo como resultado este artículo. 
Brigades against the Nationalist rebels was very high. While there is a bibliography on Jewish European or North American Jews volunteers in the Spanish Civil War, there is a conspicuous absence of historiography about the involvement of Jewish Argentines in the Iberian conflict, and very little written on Jews from Palestine in the same regard. This article looks at volunteers from these two countries and their motivation for taking an active part in the Spanish Civil War.

Keywords: Spanish Civil War, Argentina, Palestine, International Brigades, Jewish Volunteers, Mika Feldman, Pinchas Cheifetz

Desde el momento de su estallido, la Guerra Civil española adquirió una dimensión internacional. La intervención de la Alemania nazi y la Italia fascista en favor de los rebeldes, y el tardío e indeciso apoyo prestado por la Unión Soviética al Gobierno de la República hicieron a su vez de la guerra fratricida de la península ibérica un conflicto internacional (Rein \& Thomàs 2016). La guerra provocó fuertes debates en todos los países de Occidente. La opinión pública internacional liberal y de izquierdas se movilizó en favor de la Segunda República y los valores que supuestamente representaba: democracia, progreso y justicia social. Por otro lado, las fuerzas políticas conservadoras y de derechas, con todos sus matices, expresaron sus simpatías hacia la cruzada anticomunista de los nacionalistas dirigida por el general Francisco Franco.

El apoyo a la República se manifestó en campañas para recaudar fondos, alimentos y medicamentos, buscando asistirla de esta forma en el momento en el que más lo necesitaba. Pero también se expresó a través de la decisión de decenas de miles de voluntarios de todo el mundo de viajar a la península ibérica y defender la República en las trincheras.

Para analizar este fenómeno desde una perspectiva global, hay que tener en cuenta que el número de voluntarios judíos que se enrolaron en las Brigadas Internacionales para defender a la República Española de los rebeldes nacionalistas fue muy elevado. Según la mayor parte de las estimaciones, oscila entre 4.000 y 8.000 de un total de 40.000 voluntarios llegados desde unos cincuenta países (Rodríguez de la Torre 2006; Hurtado 2013; Sánchez Cervelló \& Agudo Blanco 2015; Claret 2016; Thomàs 1977). Resulta difícil establecer una estimación más precisa acerca del número total de los voluntarios en las Brigadas Internacionales. Esto es aún más difícil con respecto al número de los voluntarios de origen judío, ya que 
estuvieron diseminados entre las diversas unidades nacionales, con la excepción de aquellos que combatieron en la Compañía Naftali Botwin, llamada así en homenaje al comunista judío-polaco que había sido ejecutado por el Gobierno autoritario de Józef Klemens Pilsudski en 1925 (Zaagsma 2017; Lustinger 1991; Diamant 1979; Sichon 1988; González 2009).

Martin Sugarman ha ofrecido una serie de estadísticas, y a pesar de que quizá son algo exageradas, nos dan una idea aproximada acerca de la participación judía en la defensa de la República (Sugarman 2014). De los 5.000 voluntarios polacos, 2.250, el $45 \%$, eran judíos. En aquel entonces, los judíos representaban tan solo el $10 \%$ de la población polaca. En el caso de los EE. UU., Sugarman estima el número de voluntarios judíos en 1.250, es decir, el $38 \%$ del total de americanos alistados en las Brigadas Internacionales, en un tiempo en el que los judíos representaban solamente el $4 \%$ de la población del país. El historiador Robert Rosenstone, por su parte, estima que $30 \%$ de los voluntarios norteamericanos eran judíos (Rosenstone 1969, 368-69). Los 1.043 voluntarios franceses judíos constituyeron el $15 \%$ de todos los voluntarios del país, componiendo los judíos el o,5 \% de la población de Francia. Entre 200 y 400 judíos partieron de Gran Bretaña hacia la península ibérica, es decir, un 11-22 \% de todos los voluntarios británicos, mientras que los judíos también en este caso representaban solamente un $0,5 \%$ de la población de este país. La proporción de judíos entre los voluntarios de cada país fue, en su mayoría, muy superior a su grado de representación dentro del total de la población de esos estados (Shindler 1986; Toch 1974).

Con respecto a la Compañía Botwin, fue creada en diciembre de 1937, en el marco del Batallón Palafox de la XIII Brigada Dombrowski, polaca. Rápidamente se convertiría en un símbolo de la participación judía en la Guerra Civil, aunque la gran mayoría de voluntarios judíos no lucharían en sus filas (Zaagsma 2011, 393-397; Rothenberg 1980, 14-19). Designada oficialmente como una compañía judía, de hecho llegó a incluir también varios voluntarios no judíos, sobre todo polacos, alemanes y españoles, e incluso a dos árabes, uno de ellos un panadero de Palestina que hablaba ídish. La Compañía Botwin publicaba un boletín en el frente, llamado también Botwin, una publicación que glorificaba el apoyo judío al esfuerzo bélico republicano y a la lucha antifascista (Nuñez Díaz-Balart 2006). 
La idea inicial de llamar a la compañía Bar Kojba (el líder de la rebelión judía contra el Imperio romano en el siglo II) fue rechazada en favor de Botwin, quien había sido sentenciado a muerte tras disparar a un oficial de policía que se había infiltrado en las filas del Partido Comunista en Lviv. Botwin se transformó en un símbolo de sacrificio personal revolucionario para muchos de los afiliados al partido, judíos y no judíos por igual (Medem 1937).

La postura de muchos de estos voluntarios era internacionalista, por lo que la idea de resaltar su identidad judía les era ajena. Pese a ello, en la práctica, tal y como se refleja en muchas de las cartas que enviaron desde las trincheras o en sus memorias, yo diría que el componente judío de su identidad sí tuvo un papel crucial en sus decisiones personales de partir hacia España. La mayor parte de los voluntarios buscó detener, incluso con sus propios cuerpos en caso de ser necesario, la ola nazi y fascista que estaba asolando Europa, defendiendo de esta forma causas tanto universales como judías. Según Ethel, la esposa del médico canadiense Aaron Magid, la persecución de los judíos en Alemania fue una de las razones que empujaron a su marido a partir para España:

Bueno, estábamos escuchando todas estas cosas en Alemania acerca de lo que pasaba con los judíos, y nosotros queríamos luchar contra los fascistas, así que eso es lo que hicimos. (Petrou 2008, 38)

Obviamente, sería un error establecer ciertas generalizaciones acerca de un grupo tan numeroso de voluntarios judíos que provenían de distintos países y contaban con bagajes personales muy diversos. La decisión de cada individuo estuvo marcada por una gran variedad de factores - políticos, sociales, económicos y psicológicos. De todos modos, la destacada presencia de judíos en las Brigadas Internacionales iba a contribuir fuertemente al fortalecimiento de estereotipos antisemitas entre los nacionalistas españoles, que a menudo equiparaban a los judíos con los bolcheviques, como puede verse en las publicaciones de la Falange durante aquellos años (Álvarez Chillida 2002, \$ IV; Rohr 2008, 3). Pese a ello, aunque es posible encontrar ya una bibliografía sobre los voluntarios europeos o estadounidenses judíos (a pesar de que queda aún mucho para 
investigar al respecto), hay una conspicua ausencia en la historiografía en relación con los argentinos judíos que lucharon en la Guerra Civil española, y existen muy pocos trabajos sobre los voluntarios judíos que salieron de Palestina. Este artículo se enfoca en estos dos grupos y destaca algunas figuras judías que nos sirven para entender mejor el compromiso de miles de judíos con la República Española (Rein 2016).

\section{La movilización en la Palestina judía a favor de la República Española}

Desde su inicio a mediados de 1936, la Guerra Civil española provocó gran interés entre los judíos de Palestina. El conflicto generó una amplia gama de reacciones entre los pobladores judíos. Algunos simpatizaban con los rebeldes nacionalistas que buscaban liberar a España de lo que percibían como amenaza comunista. Otros preferían la neutralidad, siguiendo el ejemplo de Gran Bretaña, potencia a la que la Liga de Naciones había encomendado el mandato sobre Palestina. Sin embargo, la mayoría expresaba apoyo ferviente al bando republicano, un apoyo que se manifestó en colectas de dinero, alimentos y medicinas para paliar sus necesidades (Rein 2009).

A pesar de estas muestras de solidaridad con la República, prácticamente cada grupo político del Yishuv judío, incluyendo a las diversas facciones de la izquierda sionista, se opusieron al envío de jóvenes para que se sumaran a los voluntarios de las Brigadas Internacionales. Eran los tiempos de la rebelión del movimiento nacionalista palestino y de los disturbios árabes antijudíos de 1936-1939, que se cobraron las vidas de centenares de árabes, judíos y británicos. Los argumentos habituales sostenían que «el Yishuv está combatiendo por su vida misma, no menos que la República Española», y que «Hanita [un kibutz erigido en la frontera norte] tiene prioridad sobre Madrid» (Bachar 1998).

Por aquel entonces, daba la impresión de que los medios de comunicación judíos conspiraban para silenciar la historia de los voluntarios que partían hacia España con el objetivo de no alentar a otros a seguir ese camino. En los artículos que se publicaron sobre las Brigadas Internaciona- 
les, brillaba por su ausencia toda referencia a los brigadistas de Palestina, en su gran mayoría comunistas.

Hubo entre 180 y 250 voluntarios judíos que llegaron a España desde Palestina, en su mayoría miembros del Partido Comunista Palestino (PCP). Si se toma en cuenta que la población judía en Palestina por entonces no superaba la cifra de 400.000 personas, comprendemos que se trató de un número nada desdeñable. No obstante, con el correr de los años, el Partido Comunista trataría de exagerar el número de voluntarios para mejorar su imagen. La mayor parte de los trabajos escritos por miembros del PCP y sus simpatizantes sostuvieron que el número de voluntarios fue de entre 300 y 500 (Centner 1966; Levin 1987).

Los primeros combatientes del PCP que llegaron a España fueron Chaim Elkon, Imri Yaacobi y Nahum Weiss. Elkon, exjugador de futbol del Hakoah Viena, Yaacobi, uno de los futbolistas más destacados de Palestina en aquel entonces, y Weiss llegaron a Barcelona para la Olimpiada Popular que debía comenzar el 19 de julio de 1936, organizada como protesta contra los Juegos Olímpicos de Alemania (Rein 2018). Cerca de 6.ooo deportistas y unos 20.000 visitantes llegaron a Barcelona para estos juegos, que no llegaron a realizarse, incluyendo una delegación compuesta por una veintena de atletas de la asociación deportiva judeo-socialista Hapoel de Palestina (Stout 2019). Los primeros voluntarios internacionales eran, por lo tanto, militantes antifascistas que se quedaron en Barcelona.

¿Por qué, entonces, resulta tan difícil establecer el número exacto de voluntarios que salieron de Palestina para luchar en el bando de la República? ¿Eran judíos todos los voluntarios venidos de Palestina? En primer lugar, debemos especificar los criterios utilizados para determinar el número de voluntarios. ¿Debemos considerar solo a aquellos que salieron desde Palestina después del 18 de julio de 1936, o incluir también a aquellos a los que el estallido de la contienda encontró en Europa, ya fuera por estudios, visitas familiares o viajes de placer, y que cambiaron sus planes para ir a combatir en España? Si adoptamos el primer criterio, el número no supera los 145-16o. Según los datos que recopilamos de 145 voluntarios, 131 eran varones y 14 mujeres.

Como en el caso de Francia o de Bélgica, la mayor parte eran comunistas originarios de la Europa oriental o central. Eran muy jóvenes, de DICTATORSHIPS \& DEMOCRACIES \& (2020) · E-ISSN: 2564-8829 · PUNCTUM, UNIVERSITAT OBERTA DE CATALUNYA \& FUNDACIÓ CARLES PII SUNYER 
entre dieciocho y veinticuatro años de edad, mientras que, según André Malraux, $60 \%$ de los italianos voluntarios tenían más de cuarenta y cinco años, y, entre los canadienses, el 6o \% tenían más de treinta (Jackson 1986, 107). Solo una docena de ellos, aproximadamente, eran sionistas socialistas. Al menos 45 de estos voluntarios murieron en los campos de batalla ibéricos y otros 14 perecieron poco después, en la guerra mundial. Estos datos no deben sorprendernos, si se toma en cuenta el hecho de que quizá la mitad de los voluntarios extranjeros murieron en España, sin contar los que murieron después. El oficial de mayor rango entre ellos fue Mordechai Milman, caído en combate junto al Ebro (Avi-Shaul 1945). De los 145, 133 eran judíos, 7 armenios, 4 musulmanes y 1 cristiano. O sea, había una amplia mayoría judía, aunque estaban representados diversos grupos religiosos y étnicos.

Los historiadores ofrecen una variedad de explicaciones para entender la decisión tomada por estos individuos de dejar sus respectivos países para sumarse a las Brigadas Internacionales: identificación con el pueblo español, motivaciones ideológicas y económicas, un sentido romántico de la aventura. Todas ellas (y otras más) desempeñaron un papel importante a la hora de racionalizar una decisión que tendría profundas consecuencias que les iban a acompañar mientras vivieran. Sin embargo, visto en retrospectiva, no fueron las penurias económicas sino una fuerte sensación de alienación de las corrientes centrales de la sociedad judía en Palestina lo que cristalizó como la razón central para alistarse como voluntarios. En palabras de Dora Levin, que llegó a Palestina desde Polonia en 1933, cuando contaba con veintidós años de edad:

[...] Pasé unos pocos meses en el kibutz. No estaba adecuada a la vida allí, por lo que [me fui] y comencé a trabajar en todo tipo de trabajos manuales: obras de construcción, servicio doméstico. [...] Vi cómo los árabes que vivían allí [en Palestina] eran explotados. Lo que más me molestaba era que tratábamos de imponernos en trabajos que tradicionalmente eran suyos. No podía seguir viviendo así. ${ }^{1}$

1 Entrevista de D. Levin con Eran Torbiner, Haifa, Israel, mayo de 2003. Agradezco a Torbiner por compartirla conmigo. 
Michael Baron, también él nacido en Polonia, se instaló con su familia en Rusia durante la Primera Guerra Mundial y allí pasó sus años escolares, hasta que pudo regresar a su país natal en 1921. En 1929, con veinte años de edad, emigró a Palestina. Él mismo explica:

Era miembro del [movimiento juvenil sionista socialista] Hashomer Hatzair [fundado en la Europa del Este en 1913], y en 1929 llegué con mis compañeros a Palestina. Vinimos como un grupo y fuimos destinados a ayudar a los miembros de Karkur, un kibutz en crisis. [...] No tenían suficientes mujeres entre sus miembros y la atmósfera no era buena. El movimiento sionista decidió enviar algunos miembros nuevos de Hashomer Hatzair para mejorar la moral. ${ }^{2}$

Baron dejó Karkur para formar una comunidad más inclusiva y orientada hacia lo social en Shomria, pero quedó espantado por la discriminación contra los trabajadores árabes de la que fue testigo:

Lo bueno [del kibutz] fue el aspecto colectivo del trabajo. La gente no tenía que preocuparse por nada. Todo era atendido. [...] Pero comenzaron a excluir a los trabajadores árabes. El eslogan era: «Un judío emplea solo a un judío». Cuando vi eso, me puse furioso. Fui criado en los valores igualitarios del movimiento scout —el amor entre las naciones. Y aquí me topaba con odio y desprecio. ${ }^{3}$

Shmuel Shmulik Segal era más joven que Michael Baron. Su familia emigró a Palestina desde Polonia en 1926, cuando contaba con apenas ocho años de edad. Sus padres eran sionistas de larga data y su tío, Yaakov Berman, llegó a actuar como presidente del movimiento judío ortodoxo Hamizraji en Palestina. Segal recordaba el acontecimiento que lo llevó a sumarse al movimiento juvenil comunista:

Todo comenzó en la escuela secundaria, cuando llegamos a la edad en la que los estudiantes eran llamados para defender la noción del empleo judío. De vez en cuando nos convocaban para que nos presentáramos como voluntarios

2 Entrevista de Michael Baron con Eran Torbiner, Tel Aviv, noviembre de 2002.

3 Ibíd.

DICTATORSHIPS \& DEMOCRACIES 8 (2020) · E-ISSN: 2564-8829 · PUNCTUM, UNIVERSITAT OBERTA DE CATALUNYA \& FUNDACIÓ CARLES PI I SUNYER 
para trabajar, de modo que no fuera necesario emplear a trabajadores árabes. Creo que me causó una gran impresión un anciano árabe, que trabajaba como guardián. Me preguntó: «¿Y qué será de nosotros? ¿No tenemos también el derecho a ganarnos la vida?». Eso tuvo un verdadero efecto en mí. ${ }^{4}$

No obstante, a pesar de que Michael Baron, Dora Levin, Shmulik Segal y la mayor parte de los demás voluntarios eran miembros del PCP, su viaje a España no se hizo en nombre de este partido. Pese a la versión propagada por algunos exbrigadistas (como, por ejemplo, David Ostrovsky), el Partido Comunista Palestino no alentaba a sus miembros a presentarse como voluntarios para las Brigadas Internacionales. El partido en sí era pequeño y debía hacer frente a los ataques tanto de las autoridades británicas como del liderazgo del Yishuv. Tras el nombramiento del militante árabe Radwan al-Hilu como presidente del PCP en 1934, la lucha contra los imperialismos - el británico y el sionista - se convirtió en una prioridad para el liderazgo del partido, a costa de la lucha contra el fascismo, que era el núcleo del activismo de los partidos comunistas a lo largo y ancho de Europa.

Los voluntarios judíos que salieron de Palestina, guiados por su fe y un fuerte sentido de compromiso político-social, partieron como pioneros de la lucha antifascista. Algunos de ellos, sin embargo, se enrolaron en las Brigadas después de haber sido expulsados de Palestina por las autoridades británicas. La actividad comunista estaba proscrita por las autoridades, y desde comienzos de la década de 1920 era frecuente que deportaran a militantes nacidos fuera de Palestina (Beinin 1977; Dothan 1991; Ben-Zaken 2006; Zehavi 2005). Parece que en la segunda mitad de los años treinta, al menos varios comunistas estaban convencidos de que «luchar heroicamente en España es preferible a largos periodos en prisión». Un voluntario, Abraham Stockstill, relató a la comisión investigadora de la Liga de Naciones la forma en la que la policía secreta británica en Palestina lo forzó a presentarse como voluntario para luchar en España: «Estuve ocho meses en la cárcel en Palestina y S., el detective de la policía inglesa,

4 Entrevistas de Shmuel Segal con Eran Torbiner, Tel Aviv, 9 de junio de 2005, y con el autor, 26 de febrero de 2009, Tel Aviv. 
vino a mi celda amenazándome que si no iba para España me tendrían preso durante años. Preparó los papeles y me dio dinero para mis gastos del viaje» (Centner 1966, 81 y 137). David Ostrowski estuvo en prisión tres años antes de ser deportado a Francia, camino a España. Son similares las historias de Dora Levin, Pinchas Cheifetz o Ali Abdeljalek (Yahav 2008, 164-165; Ramsis 2018).

\section{Pinchas Cheifetz y su lucha por una sociedad más justa}

La vida de Pinchas Cheifetz puede servirnos como una lente adicional, o un prisma, con el que examinar el mosaico de las identidades políticas y étnico-nacionales de comunistas judíos que salieron de Palestina (y de otros países) para detener la tenebrosa ola fascista que estaba por inundar Europa. No se trataba de una identidad híbrida, sino de un mosaico típico de componentes identitarios que se encontraban en negociación permanente, destacando uno u otro componente según el contexto en el que se encontraba actuando y en un determinado momento en el tiempo. Cada uno de los componentes que formaban estas identidades nacionales, étnicas e internacionales de los voluntarios judíos se fortalecieron o se atenuaron antes de la Guerra Civil, durante su desarrollo y después de que finalizara. En el caso de Cheifetz contamos, por suerte, con un número relativamente grande de cartas que envió desde España, Francia y la URSS a sus familiares. Algunas fueron escritas en hebreo; otras en ídish (Winter \& Sivan 2000).

Cheifetz nació en 1909, en el seno de una familia con raíces profundas en Jerusalén ya desde mediados del siglo XIx. El padre de Pinchas, Chaim, falleció con apenas veintinueve años de edad, dejando a una joven viuda con dos hijos: Aharón, que entonces tenía nueve años, y Pinchas, de un año. Aharón dejó constancia en su diario de la angustia que aquejaba a la familia tras la muerte del progenitor:

Nuestra situación económica era penosa. El abuelo debía procurarnos a mi madre, a mí y a mi hermano Pinchas todo lo que necesitábamos para subsistir. Sufríamos mucho. Una vez a la semana comíamos un trozo de carne, y cada semana recibíamos por la mañana café negro con pan y mantequilla, al me- 
diodía pan y sopa de lentejas o patatas fritas y por la noche pan con aceite y un pedazo de ajo con un vaso de té y un terrón de azúcar. (Heifetz 2007, 30)

Después de un tiempo la madre resolvió dejar a los niños en el orfelinato Beit Diskin en Jerusalén, por entonces el más grande que había en Palestina. Pinchas vivió en el orfelinato desde que tenía un año hasta los trece años, cuando huyó junto con su hermano mayor. Desde jóvenes, los Cheifetz desarrollaron una aguda conciencia social y política. Aharón se convirtió en sionista socialista y Pinchas en comunista y antisionista. Se sumó a las filas del PCP y luchó contra los intentos del «imperialismo sionista por dominar Palestina».

Como militante, Cheifetz participó en numerosas y diversificadas actividades organizadas por los comunistas, incluyendo manifestaciones, actos de protesta contra la campaña sionista que impulsaba «la mano de obra hebrea» y el reemplazo de obreros árabes por judíos, y la interrupción de eventos organizados por la Histadrut, la federación general de los trabajadores judíos.

Durante los incidentes violentos entre árabes y judíos de 1929, Pinchas Cheifetz distribuyó junto con un camarada suyo panfletos antisionistas en la ciudad vieja. Para su sorpresa, fueron atacados por un grupo de árabes. Cheifetz fue acuchillado por uno de los árabes y herido en una mano, mientras que su camarada perdió la vida.

Debido a sus actividades políticas, Cheifetz fue a menudo detenido en las cárceles del mandato británico de Palestina. Chaim Flechser, uno de los líderes del Consejo Obrero de Jerusalén, contaba: «Vi cómo los ingleses lo pisoteaban sobre la calzada». Meir Gottlieb, por su parte, recordaba que «Pinchas era perseguido y golpeado más que los otros». A esto, Moshé Horenstein añadía: «La policía puso sobre él su ojo y lo detuvo a menudo. Pinchas, que era un comunista orgulloso y de una fuerza física excepcional, solía devolver los golpes a los policías británicos y por ello era confinado en aislamiento» (Heifetz 2007, 81-82).

Por aquel entonces, el PCP, que había sido fundado por un grupo de judíos de la Europa oriental, pasó por un proceso acelerado de arabización, teniendo en cuenta la mayoría árabe dentro de la población de Palestina. En Moscú abrigaban la esperanza de que el partido liderara la lucha an- 
ticolonial contra los británicos, con una propaganda que presentaba al sionismo como un movimiento nacionalista burgués que expropiaba las tierras de los árabes. Según los soviéticos, el capital judío y los fusiles británicos se habían unido (Budeiri 2010; Locker-Biletzki 2015).

Como ocurrió con otros comunistas, también el camino de Pinchas Cheifetz a España fue el resultante de diversos factores, tanto de impulso como de rechazo. Si bien caben pocas dudas sobre su identificación con la lucha antifascista que se extendía entonces por Europa, la decisión de permanecer o no en Palestina y continuar con la lucha contra el sionismo o partir hacia la península ibérica se debió a restricciones y presiones tanto por parte del Partido Comunista como de las autoridades inglesas. En una de las oportunidades en que fue nuevamente detenido, el director de la cárcel lo llamó para mantener una conversación:

Escúcheme, Cheifetz; lamentablemente nunca vamos a poder deportarlo de aquí, pues nació en esta tierra. Pero puede estar seguro que mientras nosotros gobernemos aquí, usted no saldrá de la prisión... Le proponemos que salga en libertad si viaja por su propia voluntad al extranjero. En España hay ahora una dura guerra entre los hombres del gobierno socialista y los fascistas bajo el mando del general Franco, que se sublevaron contra el gobierno. Allí, en España, se constituyó una brigada internacional de socialistas y comunistas de todo el mundo, que se presentaron como voluntarios para combatir en el bando de los socialistas españoles y darles asistencia. (Heifetz 2007, 82-83)

Cheifetz no fue el único comunista judío del que la policía británica se deshizo alentándolo a salir a España, cuando se trataba de nacidos en Palestina, o deportándolos si habían nacido en otro lugar (Arielli 2011).

Moshé Horenstein sostuvo: «El Comintern nos exigió enviar gente nacida en Palestina. Pinchas Cheifetz era uno de ellos. Fue enviado a combatir con las Brigadas Internacionales en España». Es posible, pero a fin de cuentas se trataba de la decisión personal de Pinchas, quien sentía cada vez más limitaciones en la tierra que le vio nacer. De hecho, ya en abril de 1930 había tramitado su pasaporte, aparentemente una expresión de su voluntad de irse a otro lugar donde poder vivir con mayor libertad y obtener un empleo. 
La primera escala de Cheifetz en su camino hacia los campos de batalla ibéricos fue en París. El breve lapso en el que los voluntarios de Palestina permanecían en la capital gala fue muy significativo para ellos. Los activistas del PCP, que había sido declarado ilegal y por ello debían manejarse en la clandestinidad, se embriagaban con la sensación de libertad que respiraban en la Ciudad de la Luz. Se trataba de una estadía en la que la socialización y el adoctrinamiento eran particularmente intensos (Rein \& Ofer, 2016).

Desde París Cheifetz siguió su camino hacia los Pirineos, para llegar finalmente en septiembre de 1937 a la comarca catalana de Lérida, clave en la defensa de la República (Sagués San José 2001). A comienzos de noviembre de ese año la zona fue bombardeada por la Legión Cóndor alemana, dejando 300 muertos. En los meses subsiguientes continuaron los bombardeos, hasta que entraron las tropas de Franco. En abril de 1938, Cheifetz fue herido en su cadera por una esquirla, pero continuó luchando. Poco después fue herido nuevamente y casi perdió la vista. Fue trasladado entonces a un hospital en París.

Como muchos de los voluntarios judíos de las Brigadas Internacionales, además del componente identitario político-ideológico Cheifetz tenía un marcado componente identitario étnico judío. Diez años más tarde, contaría a Miriam Shtili en la embajada israelí en Moscú: «En España me encontré a mí mismo entre numerosos judíos. Había allí por lo menos 250 jóvenes judíos de Palestina. Entre ellos un porcentaje grande de nativos y otros que estuvieron allí muchos años. La mayor parte cayó. Cuando vi que de todos los países había batallones y compañías que llevaban el nombre de héroes - la unidad en la que yo estaba llevaba el nombre de un héroe polacopropuse que la nuestra pase a llamarse Yehuda Hamacabi. Les dije que no tenía interés alguno en un héroe polaco, se llamase Cosziczko o como fuese, pero se negaron» (Heifetz 2007, 91-92).

El periódico comunista Naie Presse, que se publicaba en ídish en París, informó el 11 de abril de 1939 sobre combatientes judíos de las Brigadas Internacionales que estaban a punto de partir hacia la «patria socialista» a fin de aliviar sus vidas «y garantizar el futuro de los héroes-combatientes contra el fascismo». Entre otros aparecía mencionado Pinchas Cheifetz, nacido en Jerusalén, destacándose su participación en la compañía 
judía Naftali Botwin, cuya importancia enfatizaba el periódico durante todo el transcurso de la guerra. Cuando la nota fue publicada, Cheifetz ya se encontraba en un buque soviético rumbo hacia la URSS. Estando a bordo escribió con emoción:

Hoy se concreta el sueño de mi vida, viajo hacia mi segunda patria, la Unión Soviética. Las autoridades rusas me han reconocido como héroe de la guerra en España y han acordado acogerme hasta el fin de mi vida en un sanatorio junto a Moscú, donde podré trabajar según mi capacidad limitada [carpintería] y no deberé preocuparme más por mi sustento.

No tengo palabras para expresar mi alegría y mi felicidad por dirigirme hacia la Unión Soviética, tierra de la libertad y del socialismo. Quizás pueda ser uno de los constructores de la sociedad socialista. Así también llegará el fin a todas las persecuciones, las prisiones y todos mis sufrimientos. (Heifetz 2007, 87)

Los problemas en las comunicaciones entre Pinchas y sus parientes en Palestina no deben sorprender, dado el contexto de la guerra mundial y de la censura en la URSS. Con el trasfondo de la invasión nazi de la Unión Soviética, parece que el componente identitario étnico, si no el nacional, se fortaleció en Cheifetz. Esto se reconoce no solo en su deseo de regresar a Palestina, sino también en su alusión a «tiempos tan difíciles para nuestro pueblo y para la humanidad toda .5

El contacto entre Pinchas y sus familiares se renovó en agosto de 1947, poco antes de la votación en las Naciones Unidas sobre la partición de Palestina, periodo en el que las relaciones entre el movimiento sionista y la URSS mejoraron considerablemente, al punto de posibilitar el voto favorable de la Unión Soviética al plan de partición y la creación del Estado de Israel. Pinchas vio en esto una ventana de oportunidad que le permitiría quizás regresar a Jerusalén. En una carta redactada en ídish a su hermano le transmitía datos sobre su fecha de nacimiento, fecha de emisión de su primer pasaporte y la fecha en la que había salido de Palestina. Detrás de ello se encontraba su deseo de obtener un pasaporte nuevo y válido con el que, probablemente, podría salir de la URSS (Heifetz 2007, 91-92).

5 Pinchas Cheifetz, carta a Aharón Cheifetz, 22 marzo de 1944, archivo del autor. 
Tras la declaración de la independencia y el establecimiento de relaciones diplomáticas bilaterales entre Israel y la URSS, se abrieron sendas representaciones diplomáticas en Tel Aviv y en Moscú. Cheifetz y sus parientes en el nuevo Estado esperaban poder aprovechar las nuevas circunstancias políticas para conseguir la reunificación familiar. Pero todos sus esfuerzos fueron en vano. Por su visita a la embajada de Israel, Pinchas estaba sujeto al seguimiento de la NKVD y a menudo era molestado por los agentes de este cuerpo. La sensación de aislamiento y de ahogo que sentía fue aumentando y nuevamente se cortó el contacto con la familia. El 28 de octubre de 1958, esta recibió una carta lacónica del Maguén David Adom: «Muy señor nuestro, la Cruz Roja Rusa en Moscú nos ha solicitado notificarle que Pinas [sic] Chaimowitz Cheifetz ha fallecido el día 27 de abril de 1951. Le acompañamos en el sentimiento». ${ }^{6}$ Las circunstancias en la que se produjo la muerte no quedan del todo claras. Yaakov Cheifetz escribió en su libro: «No pasaron muchos días y en un telegrama que recibimos de la Cruz Roja decía que el cadáver de Pinchas fue hallado sobre las vías del tren junto a Moscú» (Heifetz 2007, 94-95).

\section{La Guerra española polariza la República del Plata}

Buena parte de la literatura existente sobre las vivencias judías en Argentina se ha centrado en miembros de instituciones o comunidades organizadas, y, por lo tanto, han ignorado a los voluntarios argentinos judíos que salieron a luchar en la península ibérica, la mayoría de los cuales se identificaba con el Partido Comunista Argentino (PCA) u otras corrientes de la izquierda no sionista. La historiografía argentina en torno a las reacciones al conflicto español en los países rioplatenses ha mostrado la misma actitud hacia estos argentinos judíos. Esto guarda relación con el hecho de que numerosos intelectuales de casi toda América Latina rechazan la etnicidad como categoría analítica importante, excepto cuando afecta a pueblos originarios o indígenas o de afrodescendientes (Lesser \& Rein 2007; Rein \& Aizenberg 2012; Rein \& Brodsky 2013). Además, buena parte de la historiografía sobre los partidos y movimientos de izquierda

6 Sh. Levin [de Maguen David Adom], carta a Ch. Heifetz, 28 de octubre de 1958, archivo del autor. DICTATORSHIPS \& DEMOCRACIES 8 (2020) - E-ISSN: 2564-8829 · PUNCTUM, UNIVERSITAT OBERTA DE CATALUNYA \& FUNDACIÓ CARLES PII SUNYER 
ha sido producida por intelectuales y académicos de izquierda, algunos de los cuales parecen sentirse incómodos cuando se trata de destacar la crucial presencia judía en estos marcos, particularmente durante la primera mitad del siglo xx.

Muchos argentinos judíos apoyaron a la República Española, pero no solo por una identificación ideológica con los partidos de izquierda en la península ibérica (Falcoff \& Pike 1982; Quijada 1991; Montenegro 2002; Bocanegra Barbeco 2009). Como judíos, abrigaban una preocupación adicional sobre las posibles consecuencias catastróficas del fascismo en general y del nazismo en particular. Desde su punto de vista, el apoyo brindado a la rebelión nacionalista española por la Alemania de Hitler y la Italia de Mussolini era causa de gran alarma (Rein 2014). Por otro lado, manifestar tal solidaridad transnacional con la España asediada era además una forma de promover causas sociales y étnicas en su propio país. Después de la breve experiencia traumática que supuso la dictadura de José Félix Uriburu (1930-1932), la solidaridad con España fungía incluso como recurso político para luchar contra el fascismo en Argentina. La experiencia judeo-argentina funciona aquí como un prisma a través del cual podemos discutir la relación entre la solidaridad transnacional y las formas en las que distintos grupos sociales se organizaron para promover cambios políticos y sociales. Esta incluye a los argentinos de origen judío en las geografías de la solidaridad transnacional de los años treinta, por lo que aporta una dimensión étnica a una movilización política de alcance transnacional.

La Guerra Civil en España polarizó a la sociedad argentina en bandos similares a los que se habían creado en el conflicto original. Mientras que en la Europa occidental y los Estados Unidos se veía la contienda como un enfrentamiento entre fascismo y democracia, los latinoamericanos la percibían en términos más complejos; la observaban utilizando el prisma de sus propios problemas internos, que, en muchos casos, se asemejaban a los de España en la década de 1930. Las dificultades que suponía la modernización y los obstáculos para lograrla; la necesidad de reconciliar, tanto en lo social como en lo político, constituciones decimonónicas con formas de vida moderna; los problemas vinculados a la reforma agraria; la intervención de las fuerzas armadas en la vida política; la relación en- 
tre Iglesia y Estado. Todos estos eran temas que estaban sobre el tapete en cada uno de los países hispanohablantes.

En Argentina, quizás en mayor medida que en otros lugares de América Latina, la opinión pública se inclinaba a favor de los republicanos, aunque hubo algunos elementos influyentes en la sociedad que simpatizaban con los rebeldes. Esto pudo notarse durante la presidencia de Agustín P. Justo y Roberto M. Ortiz, que apoyaban en mayor o menor grado la rebelión nacionalista liderada por el general Francisco Franco, en la creencia de que era el mejor servicio que podían dar también a los intereses nacionales de la Argentina. Sin embargo, la mayor parte de la opinión pública no estaba convencida de la necesidad de tal apoyo y continuó expresando cierto desagrado hacia la cooperación con Franco, incluso en los años que siguieron a la finalización de la contienda fratricida.

No obstante, fue el PCA quien tendría un papel crucial en la movilización de apoyo, fondos y voluntarios para la causa republicana (Piemonte 2016). Cientos de voluntarios, la mayor parte de ellos comunistas, salieron de Argentina para combatir en España, a pesar de que la embajada de la República Española en Buenos Aires no tomó parte activa en la campaña de reclutamiento y de que el gobierno incluso les creó dificultades para ir.

\section{Argentinos judíos y la causa republicana}

Mientras que muchos argentinos simpatizaban con la República como parte de su lucha por una sociedad democrática, pluralista y socialmente justa en su propio país, los argentinos judíos tenían razones adicionales para justificar su apoyo a la causa. Por un lado, estaban preocupados por el destino de aquellos parientes que estaban en Europa y por lo que podría ocurrirles en caso de surgir otro régimen tiránico con la ayuda de la Alemania nazi y la Italia fascista. Pero además buscaban proteger a la vez su espacio en Argentina, en tiempos de creciente influencia de los nacionalistas de derecha en círculos políticos, militares e intelectuales, tal y como lo expresó elegantemente Samuel Glusberg, firmando con su seudónimo, Enrique Espinoza, en un artículo titulado «Por qué los judíos deben ayudar al pueblo español», publicado en la publicación mensual Judaica, que dirigía Salomón Resnick, en julio de 1937: 
Ante todo: por una razón de justicia, que en eso consiste ser hombre y ser judío. Después, en defensa propia, porque el enemigo número uno del judío es el mismo del pueblo español. Finalmente, porque en la convivencia histórica durante siglos, solo la segunda república se apresuró a reconocer en forma oficial a los judíos.

Contra esta República se levantaron precisamente, a los pocos meses de proclamada, los generales facciosos del rey, con Sanjurjo a la cabeza, para reducir al pueblo español a la misma condición que sus muy ilustrísimos antepasados habían logrado reducir al judío...

Ahora bien, ¿puede el judío que, como el criollo, ha sentido por así decirlo en carne propia, los extremos a los que es capaz de recurrir la casta feudal y militarista en defensa de sus privilegios más odiosos, adoptar una actitud contemplativa frente a la guerra totalitaria que los últimos generales borbónicos están llevando hoy a sangre y fuego contra el pueblo español, en complicidad con las huestes negras del Duce y del Führer? De ninguna manera. El judío, para ser consecuente consigo mismo, debe de ponerse cuanto antes de parte del pueblo español en ese definitivo juego de vida o muerte y echar el resto, según la profunda expresión de nuestro idioma, en su favor. De lo contrario, tarde y temprano le ocurriría lo que al judío alemán que no supo sumarse a tiempo a la campaña contra Hitler. (Espinoza 1937)

La Comisión Israelita de Ayuda al Pueblo Español tenía quince sucursales a lo largo y ancho de Argentina, donde distribuyeron los panfletos que publicaba en ídish, y lograron recolectar no menos de 100.000 pesos en la comunidad (McGee Deutsch, 2012b, 181-182; González et al. 2008, 47). Destacados comunistas argentinos judíos tuvieron un papel importante en el Comité de Ayuda a la España Republicana o en Socorro Rojo (por ejemplo, Elsa Lola Rabinovich).

\section{Entre Moisés Ville y Madrid: voluntarios argentinos judíos}

En lo que respecta a la movilización de apoyo material para la República Española, Argentina se encontraba entre los primeros países del mundo en proporción a su población. En cuanto al número absoluto de voluntarios que combatieron en España, fue el segundo en América Latina, después 
de Cuba y antes que México. Investigaciones recientes han establecido que el número de voluntarios argentinos oscila entre los 500 y 6oo. No queda claro cuántos de ellos eran de origen judío. La lista más completa de voluntarios incluye 540 nombres de individuos que lucharon en las filas del Ejército de la República, las Brigadas Internacionales o las Milicias. Ninguno de estos voluntarios es identificado por los compiladores de la lista como judío, pero puestos en orden alfabético, los primeros son Benzión Abramson, Adelina Abramson y Paulina Abramson, y hacia el final se encuentran Zalman Izraelevich Yaselman e Hishel Zukerman.

Cuando se pasa revista a los apellidos, resulta evidente que más del $10 \%$ eran de origen judío. Obviamente, había también judíos en la Argentina, como en todas partes, que adoptaron apellidos que no son típicamente judíos. Así que la proporción de argentinos judíos entre ellos podría ser aún mayor. Según una importante autoridad en demografía judía, el número de judíos en Argentina en 1930 era de 191.400 dentro de una población total de 12 millones, o sea el 1,6 \% (Della Pergola 1987).

Varios de los judíos que pudimos identificar en esta lista eran argentinos de primera generación nacidos principalmente en la Europa oriental. La provincia de Santa Fe y la ciudad de Córdoba estuvieron claramente sobrerrepresentadas entre los voluntarios argentinos judíos. Gobernada por el radicalismo, en la provincia de Córdoba las agrupaciones de ayuda a los republicanos españoles funcionaban legalmente, sin sufrir obstáculos ni restricciones para el desarrollo de sus actividades ni persecuciones por parte de la policía.

La misma afirmación acerca de una notable representación puede hacerse para determinadas profesiones, como médicos, enfermeras, y traductores. Esto refleja que el PCA logró movilizar apoyo entre estudiantes y docentes judíos en las universidades de Buenos Aires y Córdoba, y en lo que se refiere a los traductores, muchos argentinos judíos eran bilingües o incluso trilingües. En la España Republicana, con numerosos asesores rusos y miembros de las Brigadas Internacionales provenientes de la Europa oriental, el poder comunicarse en español y también en ruso, polaco, alemán o ídish era algo muy valorado.

Gregorio Bermann, uno de los pioneros del psicoanálisis en la Argentina, se volcó de inmediato en participar en actividades en favor de los 
republicanos en la provincia de Córdoba, una vez que estalló la guerra en España. Nacido en 1896, Gregorio era el menor de ocho hermanos de una familia judía que había emigrado de Polonia. Como joven estudiante había ejercido como presidente de la Federación Universitaria de Buenos Aires y participado activamente en la dirección de Reforma Universitaria de 1918. Luego ejerció la cátedra de medicina legal de la Universidad Nacional de Córdoba, hasta que las autoridades surgidas del golpe de 1930 lo expulsaron por razones políticas. En 1932 fue candidato a gobernador de la provincia de Córdoba por su socialismo en la Alianza Civil. Hacia mediados de los años treinta ya se alejaba del socialismo y se acercaba al Partido Comunista, sin que llegase nunca a afiliarse. Al poco tiempo entendió que podía ayudar mejor a la República estando en la península ibérica, y ofreció sus servicios como médico psiquiatra al Gobierno republicano español. Publicó sus impresiones de la guerra en su libro Dialéctica del fascismo y su psicopatología. A finales de 1938 ya estaba de regreso en Argentina (Bermann 1937 y 1971). ${ }^{7}$

$\mathrm{Al}$ analizar la participación judía desde la óptica de los estudios de género, se nota claramente que la presencia judía fue sobresaliente entre las voluntarias argentinas. Sara Segal dejó la ya por entonces mítica colonia agrícola de Moisés Ville para irse a España junto con su pareja Samuel Joukovsky (Joukovsky 1998). Raquel Levenson, casada con el secretario de organización de la Federación Juvenil Comunista, Juan José Real, fue responsable del frente de educación de la Federación. Con solo veintiún años organizó el movimiento de solidaridad con España en Córdoba. Según el testimonio de su hermano Gregorio:

Nuestra actividad era de agitación y, desafiando el terror de Justo, organizábamos mítines callejeros, en los que mi hermana Raquel era la oradora infaltable, subida a un cajón, custodiada por una guardia de autodefensa integrada por rusos y polacos. Improvisábamos nuestros actos a la salida de las fábricas o en las esquinas concurridas. Antes de que llegara la policía, ya habíamos des-

7 José Luis Fitó, «Gregorio Bermann: reformista, pensador y psiquiatra», http://www.polemos. com.ar/docs/temas/Temas6/1\%AA\%2oparte\%20Gregorio\%2oBermann.htm. [Recuperado el 4 de diciembre de 2019.] 
aparecido. Aunque siempre fue así, más de una vez nos sorprendió a mitad del acto y la 'guardia', con una fidelidad a toda prueba, contenía a los esbirros mientras nosotros huíamos como podíamos. (Levenson 2000).

Poco después se fue con su marido a España, y su embarazo no supuso un obstáculo para que continuara trabajando para el partido (Comisión de Redacción de PCA, 1972). De España pasó a la Unión Soviética, donde quedaría atrapada por la Segunda Guerra Mundial. Regresó a Argentina a finales de los años cuarenta.

A Fanny Edelman le cupo un papel de liderazgo en el Comité Argentino de Mujeres Pro Huérfanos Españoles (Pieper Mooney 2013). En sus memorias, Banderas, pasiones, camaradas, cuenta que en España se dedicó a trabajar para el Socorro Rojo, organización auspiciada por los comunistas. A su regreso a la Argentina, Fanny fue promovida a miembro del Comité Central del Partido y responsable femenino del CC (Edelman 1996). Las hermanas Abramson, Paulina y Adelina, nacidas en Buenos Aires en el seno de una familia de inmigrantes judíos de Rusia, regresaron con sus padres a Moscú en 1932 y de allí fueron a España pocos meses después del comienzo de la Guerra Civil (Abramson 1994). Berta Baumkoler ya había llegado a España en 1934 con su marido. En su libro, La lucha es vida, cuenta que no se limitó a enseñar en escuelas para soldados revolucionarios o a organizar comedores, sino que también realizó guardias en cuarteles comunistas (Baumkoler 2000).

La legendaria figura de Micaela Mika Feldman (1902-1992), sin embargo, ha atraído mayor atención en los últimos años. Nació en Moisés Ville, en la provincia de Santa Fe, a comienzos del siglo xx. Sus padres, rusos judíos, habían llegado a Argentina huyendo de los pogroms. Por entonces, su padre enseñaba ídish en la colonia, patrocinada por el barón Hirsch.

Mika Feldman se convirtió en dentista y tuvo una larga trayectoria de actividad revolucionaria. El año 1919 y los episodios antisemitas de la Semana Trágica fueron decisivos para su carrera revolucionaria y la de su futuro esposo:

Llega así el año 1919 con su semana trágica del mes de enero. La huelga de Vasena paraliza la metalurgia. La revolución rusa exaspera el antisemitismo de 
los reaccionarios. Por entonces todavía se llamaba rusos a los judíos. Entre Paso y Junín, de Corrientes a Tucumán, vive «la rusada». La gentuza responsable de los disturbios obreros, causante de la lucha que llevan los obreros de Vasena en una huelga que por su magnitud y firmeza hace temblar a la burguesía y desata el frenesí argentinista de la Liga Patriótica de Carlés. Detrás de los niños bien que forman la tropa de la Liga Patriótica, entra al barrio de los rusos el escuadrón de seguridad. Para escarmiento de esos bolcheviques subversivos que venden arenques salados y pepinos, son sastres o carpinteros, los jinetes del escuadrón arrastran entre sus caballos, atados por la barba a los viejos, uncidos a las monturas de los jóvenes. Las calles se manchan de sangre. Teníamos entonces de presidente a Hipólito Irigoyen, mediante una huelga que, por su dimensión y firmeza, hacía temblar a la burguesía. (Tarcus 200o)

Tras un breve período frecuentando círculos anarquistas en Rosario, Feldman se sumó al ala izquierda del PCA en 1923, en parte por su relación con Hipólito Etchebéhère, un estudiante de ingeniería que militaba en el partido. Participó en el Comité Comunista Femenino, bregando por leyes laborales que protegieran a las mujeres trabajadoras, aunque no pasó mucho tiempo hasta que Feldman y Etchebéhère fueran expulsados por su radicalización e inclinaciones trotskistas. Fue una de las fundadoras del Partido Comunista Obrero, organización que también terminó dejando para recorrer la Patagonia con un consultorio odontológico ambulante.

En su autobiografía Mi Guerra de España, Feldman cuenta cómo a principios de la década de 1930 llegó con su pareja, Hipólito, primero a Alemania y Francia y luego a la península. Una vez allí se sumaron al Partido Obrero de Unificación Marxista (POUM), de orientación trotskista. Cobró fama cuando, tras caer Etchebéhère, asumió el mando del regimiento y obtuvo el rango de capitán. La mayor parte de los artículos y sitios web dedicados a Feldman y a su carrera revolucionaria omiten su condición de judía. A lo sumo mencionan que sus padres eran inmigrantes de la Europa oriental y que nació en Moisés Ville (Feldman 2012). Feldman mantuvo su postura antifranquista muchos años después de la derrota de la República. Efectivamente, en el período posterior a 1939 fueron muchos los argentinos, incluyendo aquellos judíos, que en- 
viaron dinero a refugiados españoles y protestaron contra las políticas brutales del general Franco (McGee Deutsch 2012a, 221-236; Rein 1993, 150-152 y 286).

Entre los voluntarios argentinos judíos, el más famoso era Simón Radowitzky. Nacido en el seno de una familia judía de trabajadores en Ucrania, Radowitzky estuvo muy involucrado en la política revolucionaria desde temprana edad. Llegó a Argentina en 1908, y pronto se unió a un grupo de anarquistas exiliados rusos. Después de la brutal represión de la manifestación del 1 de mayo de 1909, Radowitzky decidió eliminar al jefe de policía Ramón Falcón, de infame reputación reaccionaria y antisemita, asesinato por el que fue sentenciado a cadena perpetua. En 1930, como resultado de una larga campaña para asegurar su liberación, fue expulsado de Argentina. Cuando estalló la Guerra Civil española, partió hacia la península ibérica. En Aragón se reunió con una división anarquista y, más adelante, trabajó en Barcelona para la división cultural del sindicato anarquista CNT. Con la victoria de Franco, tuvo que huir a Francia, desde donde partió a México (Martí 2010).

\section{Conclusiones}

Las Brigadas Internacionales se formaron a mediados de octubre de 1936. Sin embargo, como hemos visto, los primeros voluntarios extranjeros que se pusieron al servicio de la República fueron los atletas que habían llegado a Barcelona para la Olimpiada Popular. Entre estos voluntarios la presencia judía fue nada desdeñable, incluyendo algunos deportistas de la Palestina judía.

El Comintern intentaba alistar solamente exsoldados experimentados, pero, como se notaba en los casos de la Argentina y Palestina, la mayoría de los voluntarios no habían tenido nunca un rifle en la mano antes de llegar a la península ibérica, en algunos casos por su joven edad. A diferencia de la propaganda nacionalista que sostenía que casi todos los voluntarios eran comunistas, de hecho, como en el caso argentino, las Brigadas incluyeron también a liberales, socialistas y anarquistas, y el concepto de antifascismo tenia diferentes significados para los distintos voluntarios. El grupo de voluntarios de Palestina mostró también una cierta hetero- 
geneidad, al incluir sionistas socialistas dentro de una mayoría comunista. Sabemos que no todos en las Brigadas Internacionales eran extranjeros, así como no todos los voluntarios extranjeros luchaban en el marco de las Brigadas Internacionales. Esta última afirmación es seguramente cierta para los que vinieron de Argentina. De la misma manera hemos visto que no todos los judíos luchaban en el marco de la Compañía Naftali Botwin, así como no todos los voluntarios que luchaban en el marco de esta unidad eran judíos.

El apoyo a la República durante la lucha fratricida atrajo por aquellos años en Argentina mayor participación que cualquier otro movimiento político. En parte, esto se debe a las raíces españolas de muchos argentinos, pero también a la sensación de amplios sectores de que la República confrontaba desafíos similares a los de la sociedad argentina, que a la sazón veía la creciente influencia de grupos nacionalistas, de la Iglesia católica como institución y de los círculos militares.

La presencia judía entre los argentinos que apoyaron al bando republicano fue notoria. Muchos de los judíos participaban en movimientos sindicales y de izquierda del país ya desde antes, y en los años treinta consideraron vital enfrentarse y oponer resistencia a todo aquello que se pareciera al fascismo, dentro y fuera de Argentina. No debe sorprender, por consiguiente, que se sumaran a una variedad de manifestaciones de solidaridad con la República Española, luchando por su supervivencia contra sus enemigos nacionalistas, que contaban con el apoyo de la Alemania hitleriana y la Italia de Mussolini. Al combatir la causa fascista defendían sus propios espacios en Argentina y luchaban por un mayor pluralismo, democracia y justicia social. Para ellos, como para tantos otros judíos en muchos países, se trataba de una lucha transnacional con metas nacionales (argentinas, francesas o estadounidenses).

Desde la perspectiva de género y el enfoque biográfico de voluntarias como Dora Levin, Mika Feldman o Fanny Edelman, vemos que su actuación tenía que ver también con la lucha acerca del lugar de la mujer en la sociedad. Numerosos voluntarios en la Guerra Civil, independientemente de sus países de origen, eran de tendencias internacionalistas y no enfatizaban el componente judío en su identidad. No obstante, hay un punto que queda claro: la proporción de judíos entre los voluntarios de cada 
país fue, en la mayor parte de los casos, muy superior a su equivalente en la población general de ese país.

Cuando se investiga la Palestina de la década de 1930 y las actitudes contemporáneas de los partidos políticos judíos, de diversas asociaciones civiles y de la prensa local, resulta evidente que una considerable mayoría se movilizó para apoyar a la República Española. La historiografía ha tendido a sobreestimar el compromiso del PCP en dicho apoyo y ha asumido que fue inmediato, inequívoco e incondicional. Simultáneamente hay una tendencia a subestimar el compromiso de la izquierda sionista con la causa republicana. Si bien es verdad que la mayor parte de los líderes sionistas, incluyendo los de izquierda, se opusieron a que jóvenes judíos de Palestina fueran a luchar a España, sí manifestaron su apoyo a la causa republicana en una amplia gama de maneras. El alcance de este compromiso fue tal que incluso diez años después de terminado el conflicto armado, el Estado de Israel recientemente establecido dudaba aún si establecer o no vínculos formales con el régimen impuesto por el líder nacionalista, el generalísimo Francisco Franco, vencedor de la Guerra Civil.

\section{Bibliografía}

Abramson, Paulina y Adelina. 1994. Mosaico roto. Madrid: Compañía Literaria. Álvarez Chillida, Gonzalo. 2002. El antisemitismo en España. Madrid: Marcial Pons. Arielli, Nir. 2011. «Induced to Volunteer? The Predicament of Jewish Communists in Palestine and the Spanish Civil War». Journal of Contemporary History 46 (4): 84487o. doi: https://doi.org/10.1177/0022009411413406.

Avi-Shaul, Mordechai. 1945. A Hebrew Commander in Embattled Spain. Tel Aviv: s. e. [En hebreo.]

Bachar, Moshe. 1998. «Hanita is Preferable to Madrid: The Reaction of the Yishuv in Palestine to the Civil War in Spain». Tesis de maestría, Tel Aviv University. Baumkoler, Berta. 200o. La lucha es vida. Buenos Aires: Cuadernos Marxistas. Beinin, Joel. 1977. «The Palestine Communist Party, 1919-1948». MERIP Reports 55 (marzo): 3-16. doi: https://doi.org/10.2307/3010830.

Ben-Zaken, Avner. 20o6. Communism as Cultural Imperialism. Tel Aviv: Resling. [En hebreo.]

Bermann, Gregorio. 1971. Conciencia de nuestro tiempo. Buenos Aires: Hernández. -1937. Dialéctica del fascismo y su psicopatología. Madrid: Psicoterapia. 
Bocanegra Barbeco, Lidia. 2009. «La República Argentina: el debate sobre la guerra civil y la inmigración». Dentro Abdón Mateos, ed., Ay de los vencidos. El exilio y los países de acogida, 189-234. Madrid: Eneida.

Budeiri, Musa. 2010. The Palestine Communist Party, 1919-1948: Arab and Jew in the Struggle for Internationalism. Londres: Haymarket.

Centner, Israel. 1966. From Madrid to Berlin. Tel Aviv: s. e. [En hebreo.]

Claret, Jaume. 2016. Breve historia de las Brigadas Internacionales. Madrid: Catarata.

Comisión de Redacción de PCA. 1972. Raquel Levenson, ejemplo de una mujer revolucionaria. Buenos Aires: Frente Unido.

Della Pergola, Sergio. 1987. «Demographic Trends of Latin American Jewry». Dentro Judith Laikin Elkin y Gilbert W. Merks, ed., The Jewish Presence in Latin America, 85133. Boston: Allen \& Unwin.

Diamant, David. 1979. Combattants juifs dans L’Armée Republicaine Espagnole 1936-1939. París: Renouveau.

Dothan, Shmuel. 1991. Reds: The Communist Party in Palestine. Kfar Saba: Shvana HaSofer. [En hebreo.]

Edelman, Fanny. 1996. Banderas, Pasiones, Camaradas. Buenos Aires: Dirple.

Espinoza, Enrique [Samuel Glusberg]. 1937. «Por qué los judíos deben ayudar al pueblo español». Judaica 5, No. 49, p. 1 (jul.).

Falcoff, Mark, y Fredrick B. Pike, ed. 1982. The Spanish Civil War, 1936-1939: American Hemispheric Perspectives. Lincoln: University of Nebraska.

Feldman, Mika. 1987. Mi guerra de España. Madrid: Plaza y Janés.

Fitó, José Luis. «Gregorio Bermann: reformista, pensador y psiquiatra». http://www. polemos.com.ar/docs/temas/Temas6/1\%AA\%2oparte\%20Gregorio\%2oBermann. htm [Consultado el 4 de diciembre de 2019.]

González, Isidro. 2009. Los judíos y la Guerra Civil Española. Madrid: Hebraica.

González, Lucas, et al. 2008. Voluntarios de Argentina en la Guerra Civil Española. Buenos Aires: Ediciones del Centro Cultural de la Cooperación Floreal Gorini.

Heifetz, Yaacov. 2007. Grandpa's Reminiscences. Ramat Ha-Sharon: s. e. [En hebreo.] Hurtado, Víctor. 2013. Atlas de la Guerra Civil española. Las Brigadas Internacionales. Barcelona: DAU.

Jackson, M. W. 1986. «The Army of Strangers: The International Brigades in the Spanish Civil War». Australian Journal of Politics \& History 32 (1): 105-118. doi: https://doi. org/10.111/j.1467-8497.1986.tboo344.x.

Joukovsky, Samuel. 1998. Uno de tantos. Un argentino en la guerra civil española. Buenos Aires: s. e.

Levenson, Gregorio. 2000. De los bolcheviques a la gesta montonera. Buenos Aires: Colihue.

Levin, Ruth. 1987. The Righteous Were with Spain. Tel Aviv: Ofakim. [En hebreo.] Locker-Biletzki, Amir. 2015. The Holidays of Revolution. Myth, Ritual and Identity among Tel Aviv Communists, 1919-1965. Ontario: University of Guelph.

Lustiger, Arno. 1991. Schalom Libertad! Juden im Spanischen Bürgerkrieg. Colonia: Kiepenheuer \& Witsch. 
Martí, Alejandro. 2010. Simón Radowitzky: del atentado a Falcón a la guerra civil española. Buenos Aires: De la Campana.

McGee Deutsch, Sandra. 2012a. «Argentine Women Against Fascism: The Junta de la Victoria, 1941-1947». Politics, Religion \& Ideology 13 (2): 221-236. doi: https://doi.org/ 10.1080/21567689.2012.675707.

McGee Deutsch, Sandra. 2012b. Crossing Borders, Claiming a Nation: A History of Argentine Jewish Women, 1880-1955. Durham: Duke University Press.

Medem, Gina. 1937. Los judíos luchadores de la libertad: un año de lucha en las Brigadas Internacionales. Madrid: Ediciones del Comisariado de las Brigadas Internacionales.

Montenegro, Silvina. 2002. «La Guerra Civil española y la política argentina». Tesis doctoral, Universidad Complutense de Madrid.

Nuñez Díaz-Balart, Mirta. 2006. La disciplina de la conciencia: las Brigadas Internacionales y su artillería de papel. Barcelona: Flor del Viento.

Osorio, Elsa. 2012. La Capitana. Madrid: Siruela.

Piemonte, Víctor Augusto. 2016. «Las prácticas políticas del Partido Comunista de la Argentina ante la guerra civil española y su relación con la Internacional Comunista». Historia Contemporánea 52: 179-209. doi: https://doi.org/10.1387/ hc.15738.

Pieper Mooney, Jadwiga E. 2013. «El antifascismo como fuerza movilizadora: Fanny Edelman y la Federación Democrática Internacional de Mujeres (FDIM)», Anuario IEHS 28: 207-226.

Petrou, Michael. 2008. Renegades: Canadians in the Spanish Civil War. Vancouver: UBC Press.

Quijada, Mónica. 1991. Aires de república, aires de cruzada: la guerra civil española en Argentina. Barcelona: Sendai.

Ramsis, Amal, dir. 2018. You Come from Far Away, documental. España/Líbano/Egipto/ Catar: Klaketa Árabe / Morgana Producciones.

Rein, Raanan. 1993. The Franco-Perón Alliance: Relations Between Spain and Argentina 1946-1955. Pittsburgh: University of Pittsburgh Press.

- 2009. «Las repercusiones de la guerra civil española en Palestina: sionistas y comunistas, judíos y árabes». Revista de Historia Contemporánea 38: 89-112.

_. 2014. «Metas nacionales y étnicas en una lucha transnacional: argentinosjudíos en solidaridad con el bando republicano durante la Guerra Civil Española». Investigaciones y Ensayos 61: 405-425.

- 2016. «Tikkun Olam and Transnational Solidarity: Jewish Volunteers in the Spanish Civil War». Politics and Religion 10 (2): 207-230.

—_. 2018. «El desafío a los Juegos Olímpicos de Berlín 1936: los atletas judíos de Palestina en la frustrada Olimpiada Popular de Barcelona». Revista de Historia Contemporánea 56: 121-155. doi: https://doi.org/10.1387/hc.17596.

Rein, Raanan, y Inbal Ofer. 2016. «Becoming Brigadistas: Jewish Volunteers from Palestine in the Spanish Civil War». European History Quarterly 46 (1): 92-112. doi: https://doi.org/10.1177/0265691415620956. 
Rein, Raanan, y Adriana Brodsky, ed. 2013. The New Jewish Argentina: Facets of Jewish Experiences in the Southern Cone. Boston: Brill.

Rein, Raanan, y Edna Aizenberg. 2012. Contra la corriente: nuevos estudios sobre los latinoamericanos judíos, monográfico. Estudios Interdisciplinarios de América Latina y el Caribe 23 (1).

Rein, Raanan, y Jeffrey Lesser. 2007. «Nuevas aproximaciones a los conceptos de etnicidad y diáspora en América Latina: la perspectiva judía». Estudios Sociales 32: 11-30. doi: https://doi.org/10.14409/es.v32i1.2586.

Rein, Raanan, y Joan Maria Thomàs, ed. 2016. Guerra Civil y franquismo: Una perspectiva internacional. Zaragoza: Universidad de Zaragoza.

Rodríguez De la Torre, Fernando. 2006. Bibliografía de las Brigadas Internacionales y de la participación de extranjeros a favor de la República, 1936-1939. Albacete: Instituto de Estudios Albacetenses Don Juan Manuel de la Diputación de Albacete.

Rohr, Isabelle. 2008. The Spanish Right and the Jews, 1898-1945: Antisemitism and Opportunism. Brighton: Sussex University Press.

Rosenstone, Robert. 1969. Crusade of the Left: The Lincoln Battalion in the Spanish Civil War. New York: Pegasus.

Rothenberg, Joshua. 1980. «The Jewish Naftali Botwin Company». Jewish Frontier 47 (4): 14-19.

Sagués San José, Joan. 2001. «Lleida en la Guerra Civil espanyola (1936-1939)». Tesis doctoral, Universitat de Lleida.

Sánchez Cervelló, Josep, y Sebastián Agudo Blanco, ed. 2015. Las Brigadas Internacionales: nuevas perspectivas en la historia de la Guerra Civil y del exilio. Taragona: Universitat Rovira i Virgili.

Shindler, Colin. 1986. «No Pasarán. The Jews who fought in Spain». The Jewish Quarterly 33: 34-41.

Sichon, Gaby Ersler. 1998. «Les volontaires juifs dans la guerre civile en Espagne: chiffres et enjeux». Les Temps Modernes 44 (507): 46-62.

Stout, James. 2019. The Popular Front and the Barcelona 1936 Popular Olympics. Singapur: Palgrave MacMillan.

Sugarman, Martin. 2014. «Against Fascism-Jews who served in The International Brigade in the Spanish Civil War». https://www.jewishvirtuallibrary.org/jsource/ History/spanjews.pdf. [Consultado el 25 de noviembre de 2019.]

Tarcus, Horacio. 2000. «Historia de una pasión revolucionaria. Hipólito Etchebéhère y Mika Feldman, de la reforma universitaria a la guerra civil española». El Rodaballo. Revista de Política y Cultura 11 (12): 38-51.

Thomas, Hugh. 1977. Tercera edición. The Spanish Civil War. Harmondsworth: Penguin.

Toch, Josef. 1974. «Jews in the Civil War in Spain, 1936-39». Basha'ar 17: 456-66. [En hebreo.]

Winter, Jay, y Emmanuel Sivan, ed. 2000. War and Remembrance in the Twentieth Century. Nueva York: Cambridge University Press.

Yahav, Dan. 2008. They Too Were Heroes: Volunteer Fighters from Eretz Israel in the International Brigades in Spain. Tel Aviv: Chericover. [En hebreo.] 
Zaagsma, Gerben. 2017. Jewish Volunteers, the International Brigades, and the Spanish Civil War. London: Bloomsbury.

—. 2011. «Die Botwin Kompagnie». Dentro Dan Diner, ed., Enzyklopädie jüdischer Geschichte und Kultur. Band 1: $\mathrm{A}-\mathrm{Cl}$, 392-397. Stuttgart/Weimar: Metzler.

Zehavi, Leon. 2005. Apart or Together: Jews and Arabs in Palestine according to the Documents of the Comintern. Jerusalén: Keter. [En hebreo.] 